\title{
COVID-19 pneumonia imaging follow-up: when and how? A proposition from ESTI and ESR
}

\author{
K. Martini ${ }^{1}$ (1) A. R. Larici ${ }^{2} \cdot$ M. P. Revel ${ }^{3} \cdot$ B. Ghaye ${ }^{4} \cdot$ N. Sverzellati ${ }^{5} \cdot$ A. P. Parkar ${ }^{6} \cdot$ A. Snoeckx ${ }^{7} \cdot$ N. Screaton ${ }^{8}$. \\ J. Biederer ${ }^{9,10,11,12} \cdot$ H. Prosch ${ }^{13} \cdot$ M. Silva ${ }^{5} \cdot$ A. Brady ${ }^{14} \cdot$ F. Gleeson $^{15} \cdot$ T. Frauenfelder $^{1} \cdot$ On behalf of the European \\ Society of Thoracic Imaging (ESTI), the European Society of Radiology (ESR)
}

Received: 29 June 2021 / Revised: 20 August 2021 / Accepted: 4 September 2021 / Published online: 29 October 2021

(c) The Author(s) 2021

\begin{abstract}
This document from the European Society of Thoracic Imaging (ESTI) and the European Society of Radiology (ESR) discusses the role of imaging in the long-term follow-up of COVID-19 patients, to define which patients may benefit from imaging, and what imaging modalities and protocols should be used. Insights into imaging features encountered on computed tomography (CT) scans and potential pitfalls are discussed and possible areas for future review and research are also included. Key Points

- Post-COVID-19 pneumonia changes are mainly consistent with prior organizing pneumonia and are likely to disappear within 12 months of recovery from the acute infection in the majority of patients.

- At present, with the longest series of follow-up examinations reported not exceeding 12 months, the development of persistent or progressive fibrosis in at least some individuals cannot yet be excluded.

- Residual ground glass opacification may be associated with persisting bronchial dilatation and distortion, and might be termed "fibrotic-like changes" probably consistent with prior organizing pneumonia.
\end{abstract}

Keywords COVID-19 $\cdot$ Diagnostic imaging $\cdot$ Multidetector computed tomography $\cdot$ Lung $\cdot$ Follow-up

K. Martini

katharina.martini@usz.ch

1 Institute of Diagnostic and Interventional Radiology, University Hospital Zurich, Rämistrasse 100, 8091 Zurich, Switzerland

2 Department of Diagnostic Imaging, Oncological Radiotherapy and Hematology, Fondazione Policlinico Universitario “A. Gemelli” IRCCS, Università Cattolica del Sacro Cuore, Rome, Italy

3 Department of Radiology, Cochin Hospital, Université de Paris, Paris, France

4 Department of Radiology, Cliniques Universitaires Saint Luc, Catholic University of Louvain, Brussels, Belgium

5 Scienze Radiologiche, Department of Medicine and Surgery, University of Parma, Parma, Italy

6 Department of Radiology, Haraldsplass Deaconess Hospital and Department of Clinical Medicine, Faculty of Medicine and Dentistry, University of Bergen, Bergen, Norway

7 Department of Radiology, Antwerp University Hospital and University of Antwerp, Antwerp, Belgium
8 Department of Radiology, Royal Papworth Hospital, Cambridge, UK

9 Department of Diagnostic and Interventional Radiology, University Hospital of Heidelberg, Heidelberg, Germany

10 Member of the German Lung Research Center (DZL), Translational Lung Research Center Heidelberg (TLRC), Im Neuenheimer Feld 430, 69120 Heidelberg, Germany

11 Faculty of Medicine, University of Latvia, Raina bulvaris 19, Riga 1586, Latvia

12 Faculty of Medicine, Christian-Albrechts-Universität Zu Kiel, 24098 Kiel, Germany

13 Department of Biomedical Imaging and Image-Guided Therapy, Medical University of Vienna, Vienna, Austria

14 Department of Radiology, Mercy University Hospital, Cork, and University College Cork, Cork, Ireland

15 Department of Oncology, University of Oxford, Oxford, UK 


$\begin{array}{ll}\text { Abbreviations } \\ \text { AI } & \text { Artificial intelligence } \\ \text { ARDS } & \text { Acute respiratory distress syndrome } \\ \text { COVID-19 } & \text { Corona virus 2019 } \\ \text { CT } & \text { Computed tomography } \\ \text { CTPE } & \text { CT pulmonary angiography } \\ \text { DECT } & \text { Dual-energy computed tomography } \\ \text { DLCO } & \text { Diffusing capacity } \\ \text { ERS } & \text { European Respiratory Society } \\ \text { ESR } & \text { European Society of Radiology } \\ \text { ESTI } & \text { European Society of Thoracic Imaging } \\ \text { GGOs } & \text { Ground glass opacities } \\ \text { ICU } & \text { Intensive care units } \\ \text { ISTH } & \text { International Society of Thrombosis and } \\ & \text { Haemostasis } \\ \text { MERS } & \text { Middle East respiratory syndrome } \\ \text { minIP } & \text { Minimum intensity projection } \\ \text { PE } & \text { Pulmonary embolism } \\ \text { PET } & \text { Positron emission tomography } \\ \text { RT-PCR } & \text { Real-time polymerase chain reaction } \\ \text { SARS } & \text { Severe acute respiratory syndrome } \\ \text { SSC } & \text { Scientific and Standardization Committee } \\ \text { VAP } & \text { Ventilator-associated pneumonia } \\ \text { VTE } & \text { Venous thromboembolism } \\ & \end{array}$

\section{Background}

The term "long COVID" was first mentioned in the literature in June 2020 [1]. In autumn 2020, olfactory symptoms, mainly the loss of smell or altered sense of smell, were the first reported persisting symptoms, followed by recognition that symptoms could linger in all parts of the body [1]. The British Medical Journal guidelines define persistent symptoms after 4 weeks as long COVID, and post-COVID syndrome when symptoms last longer than 12 weeks [1]. It affects about $10 \%$ of COVID-19 patients [2, 3]. The risk of developing long COVID or post-COVID syndrome is dependent on several factors, including the severity of the primary infection, age, gender, and body mass index [3]. In addition, the need for admission to and the duration of admittance to intensive care units (ICU) and mechanical ventilation, plus possible smoking history and chronic alcoholism, have also been cited as potential risk factors for the development of persisting pulmonary abnormalities following COVID-19 pneumonia [4].

The incidence of COVID-19 pneumonia patients managed with mechanical ventilation has been reported as being between 29 and $89 \%$ [5], with the numbers varying as papers report the incidence of ventilation, with this varying across the world and changing over the course of the pandemic. Ventilator-associated pneumonia (VAP) is defined as pneumonia which occurs after $48 \mathrm{~h}$ of mechanical ventilation
[6]. COVID-19 pneumonia patients have an increased risk of VAP, with $48 \%$ of patients developing VAP compared to $13 \%$ in non-COVID-19 pneumonia patients [7].

The risk of developing pulmonary fibrosis after acute respiratory distress syndrome (ARDS) is well known and was recognized long before COVID-19 pneumonia $[8,9]$. Previous pulmonary infection resulted in fibrosis in $4 \%$ after the first severe acute respiratory syndrome (SARS) epidemic in the early 2000s [10] and up to 25\% after H1N1 [11]. The rate of suspected lung fibrosis on CT in COVID-19 pneumonia patients varies between about $46 \%$ at 2 months and $25-30 \%$ at 3 months and 6 months respectively [12-14]. Longerterm follow-up studies are awaited to determine if these CT features will persist or resolve.

However, pulmonary dysfunction is not the only longterm symptom. Several other symptoms may persist and present as thromboembolic, cardiovascular, neuropsychiatric, renal, gastrointestinal, or dermatological disease [15]. The most common self-reported symptoms are fatigue, dyspnea, headache, and loss of sense of smell [3]. The purpose of this paper is to describe the role of imaging in long COVID patients and post-COVID syndrome. Clinical aspects in the follow-up of COVID-19 patients can be found in a statement (currently under review) from the European Respiratory Society (ERS).

\section{Role of Imaging}

\section{What are the $\mathrm{CT}$ features encountered in patients after COVID-19 pneumonia?}

\section{CT features at discharge}

The sequential pulmonary alterations during the early stage of the acute phase of COVID-19 pneumonia include peripheral and bilateral ground glass opacities (GGOs) as the predominant findings, followed, as the disease progresses, by consolidation that gradually resolves in survivors [16]. Some patients were reported to develop cystic lung disease, such as pneumatoceles. However, these changes are mostly due to barotrauma during mechanic ventilation (ventilationassociated lung injury) [17, 18]. Radiological appearances of cyst formation secondary to COVID-19 are reported, but with relatively low prevalence [19].

The rate of full resolution at patient discharge varies between studies, according to the initial severity of the infection; indeed, the full representation of imaging follow-up is not known (e.g., patients with minor signs of acute pneumonia are less likely to undergo follow-up with pulmonary imaging). Lung consolidation has been reported to show faster improvement [20]. Patients at 
discharge may therefore present with normal lungs or residual GGO as the most frequent pulmonary appearance on CT [20, 21].

Residual disease at discharge has been reported in up to $94 \%$ of patients [22]. Interestingly, GGO may first extend further in the lungs while decreasing in attenuation, a phenomenon reported as the "tinted sign," possibly reflecting a gradual regression of inflammation associated with reexpansion of the alveoli [12, 20] (Fig. 1). Most residual disease will further regress, and complete recovery has been reported in $25-42 \%$ at 2 weeks and $53-65 \%$ at 3 to 4 weeks after discharge [20, 21]. Consequently, imaging follow-up should be performed after a delay to allow resolution of the reversible inflammatory process. There are recommendations to perform CT follow-up at 12 weeks post discharge in patients with persistent respiratory symptoms, after clinical assessment and pulmonary function test evaluation [23].

\section{CT features at three months}

At 3 months, there are remaining $\mathrm{CT}$ abnormalities reported in 17 to $91 \%$ of discharged COVID-19 pneumonia patients [13, 24-27]. The highest range was reported in patients who were admitted to ICU [28], while it is expected that patients with minor signs of acute pneumonia might reverse in the vast majority of cases.

Low-attenuation GGO remains the most frequent CT finding, observed in up to two-third or more of patients [13, 24-26]. Other CT findings include linear consolidation or band-like and perilobular opacities, possibly in part consistent with organizing pneumonia, and also reticulation and interstitial thickening (Figs. 2, 3, and 4). A greater extent of CT abnormalities is associated with longer hospitalization, ICU admission, and ventilation [24, 29].

Fibrotic-like lung changes on $\mathrm{CT}$ such as reticulation associated with traction bronchiectasis have been
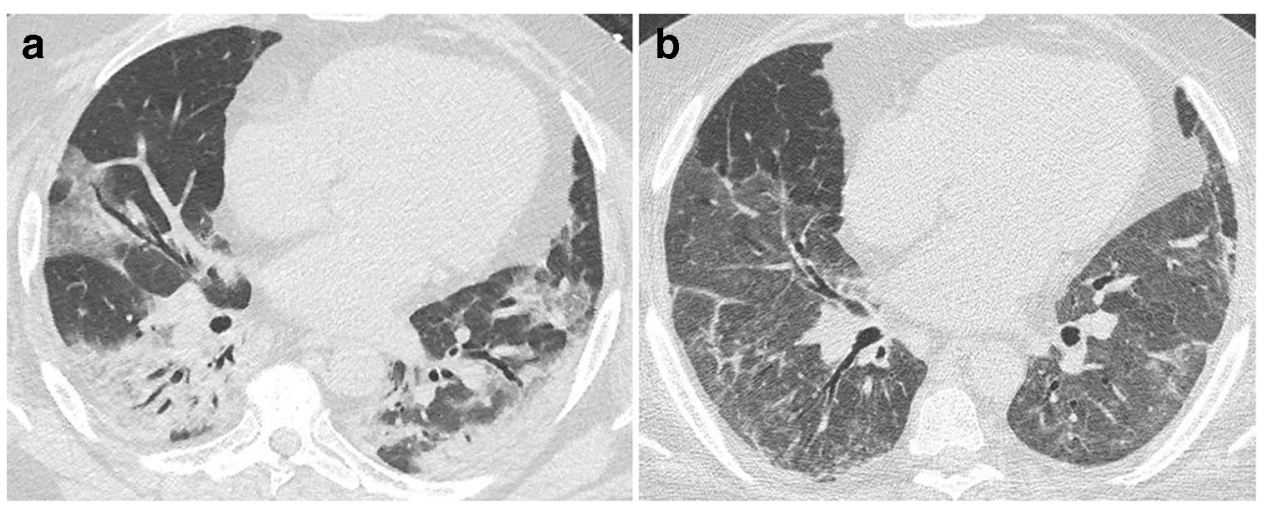

Fig. 1 CT features at baseline and at discharge in a 52-year-old man who developed severe COVID-19 pneumonia (intubation, extracorporeal membrane oxygenation, 45 days in ICU). a Baseline CT showing bilateral consolidation and ground glass opacities (GGOs) with peripheral and peribronchovascular distribution. b 2-month CT fol- low-up demonstrating the complete resolution of consolidation, with residual parenchymal bands bilaterally, while GGOs appear more extensive ("tinted sign") in the lower lobes, lingula, and right middle lobe. Note the improved expansion of the left lung in $\mathbf{b}$
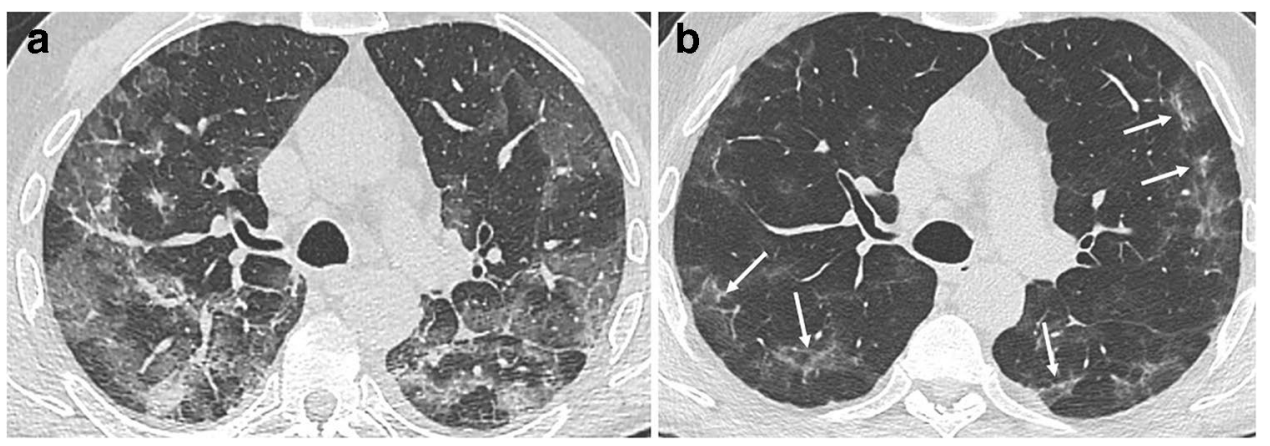

Fig. 2 CT features at baseline and 3-month follow-up, in a 60-yearold man with initial medium severity (10-day oxygen supplementation). a Baseline CT showing bilateral peripheral ground glass opacities (GGOs). b 3-month CT follow-up. GGOs significantly improved. Some areas of linear consolidation parallel to the pleura are demon- strated (arrows), consistent with late phase organizing pneumonia. Mild deformation of the left major fissure is noted, but there are no formal signs of fibrosis such as traction bronchiectasis or honeycombing 
Fig. 3 CT features at baseline, and 4-month follow-up, in a 52-year-old woman who developed severe COVID-19 pneumonia (intubation, 42 days in ICU). a Baseline CT. b, c 4-month CT follow-up. Ground glass opacities (GGOs) have partially resolved (low-density GGO), with remaining linear opacities on the axial transverse view through the upper lung (b). On the sagittal reformation (c), the polygonal shape suggests that linear opacities on the axial transverse view have a perilobular distribution (d, magnification), which might indicate late phase organizing pneumonia
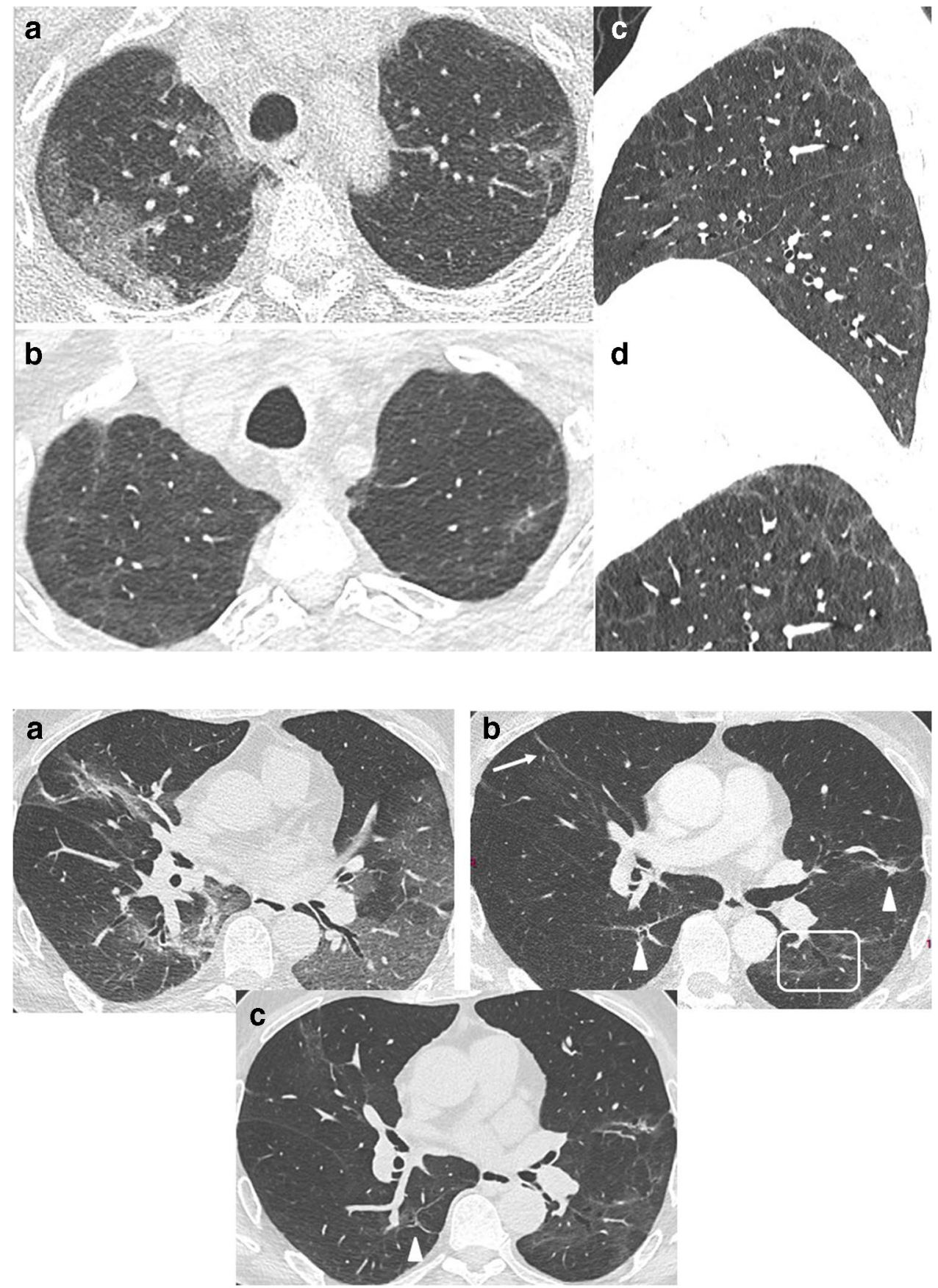

1
Fig. 4 CT features at baseline and 4-month and 1-year followup, in a 65-year-old man who developed severe COVID-19 pneumonia (intubation, 27 days in ICU). a Baseline CT. b 4-month CT follow-up. Ground glass opacities (GGOs) have largely resolved, except in the upper segment of the left lower lobe. Bronchial dilatation (square) is demonstrated within the residual GGO area. Linear consolidation (arrow head) and parenchymal band (arrow) are also denoted. c 1-year followup. CT features are unchanged. There are no honeycombing and no peripheral reticulations

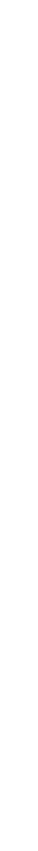

\section{.}


Fig. 5 CT features at baseline, and 1-year follow-up, in a 30-year-old woman who developed severe COVID-19

pneumonia (intubation, 40 days in ICU). a, b Baseline CT showing extensive ground glass opacities (GGOs) and consolidation. c-g 1-year CT follow-up. Residual GGO, with a linear shape, is mainly seen in the upper lung, suggestive of organizing pneumonia at a late phase. There is no bronchial dilatation, signs of architectural distortion, or honeycombing, as confirmed by minimum intensity projections (minIP) $(\mathbf{e}, \mathbf{f}, \mathbf{g})$. The sagittal minIP reformations (f, $\mathbf{g})$ demonstrate plurilobular areas of decreased attenuation (arrows). This mosaic attenuation pattern might be due to either residual small airway disease or peripheral vascular obstruction. DLCO at 1 year was $64 \%$
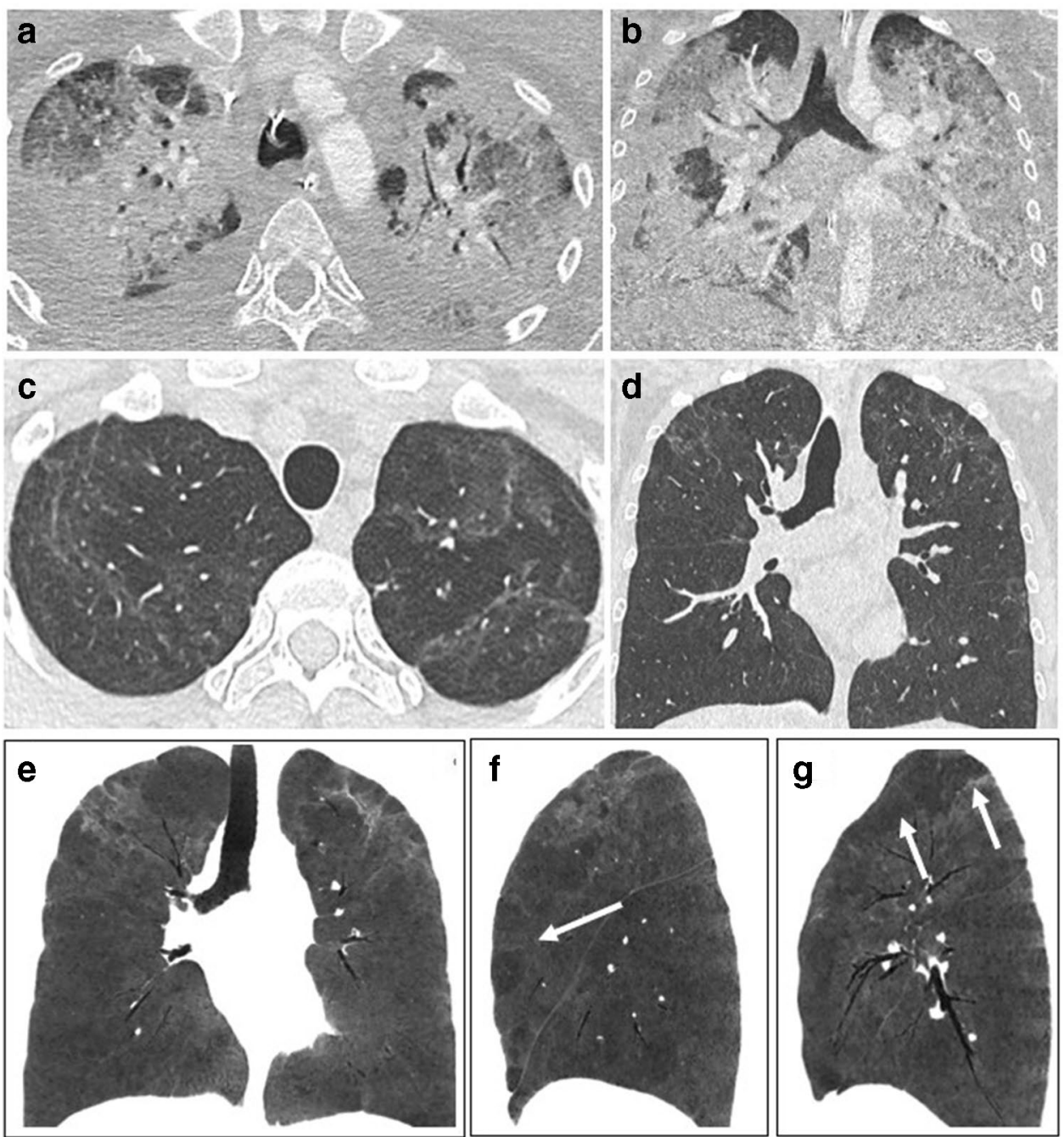

\section{CT features at longer-term follow-up}

While short-term follow-up CT findings have now been largely described, there are fewer reports on longer-term follow-up appearances.

Han et al reported "fibrotic-like" changes at 6-month follow-up in 35\% of COVID-19 patients who had severe disease, according to the World Health Organization's interim guidance diagnostic criteria [12]. These "fibroticlike" changes included traction bronchiectasis (Figs. 4 and 6) and honeycombing, as well as interlobar pleural traction and thickening of the pleura, the latter two being more questionable. Honeycombing and traction bronchiectasis were respectively observed in 2 and $10 \%$ of patients at 6 months.

It is unclear whether the reported "so-called" traction bronchiectasis represents irreversible change, as it has been reported in survivors of the preceding SARS epidemic that $\mathrm{CT}$ abnormalities present at 6 months may show improvement at 84-month follow-up [32].
In a recent report, 27 of 41 patients (61\%) evaluated at 7 months, of whom 15 had initially severe disease, achieved complete radiological resolution on the 7-month follow-up CT, with persisting bronchial distortion present in 29\% [33].

It is important to be aware that in ARDS survivors, it has been reported that long-term disability is mainly due to causes other than lung fibrosis, with mild abnormalities only identified on CT performed between the 2-year and 5-year visits [34].

In keeping with these reports, the currently available longest follow-up series on 83 patients after survival of severe COVID-19 pneumonia reports a high prevalence of residual findings on $\mathrm{CT}$ at discharge from the hospital, with a continuous improvement 12 months after discharge [35]. In this study, the number of individuals with residual changes on CT improved from 65 (78\%) at 3 months after discharge from hospital to $40(48 \%)$ at 6 months, $22(27 \%)$ at 9 months, and $20(24 \%)$ at 12 months after discharge. Together with the reduction of $\mathrm{CT}$ abnormality prevalence, the spectrum of findings changed: typical features of COVID-19 pneumonia 
Fig. $6 \mathrm{CT}$ features at baseline, and 1-year follow-up, in a 63-year-old man who developed severe COVID-19 pneumonia (intubation, 9 days in ICU). a Baseline CT. b 1-year CT follow-up. Ground glass opacities (GGOs) have largely resolved. Mild bronchial dilatation (rectangle) is demonstrated within the residual GGO area of the right lower lobe. Pulmonary function tests are normal, with a DLCO value of $90 \%$
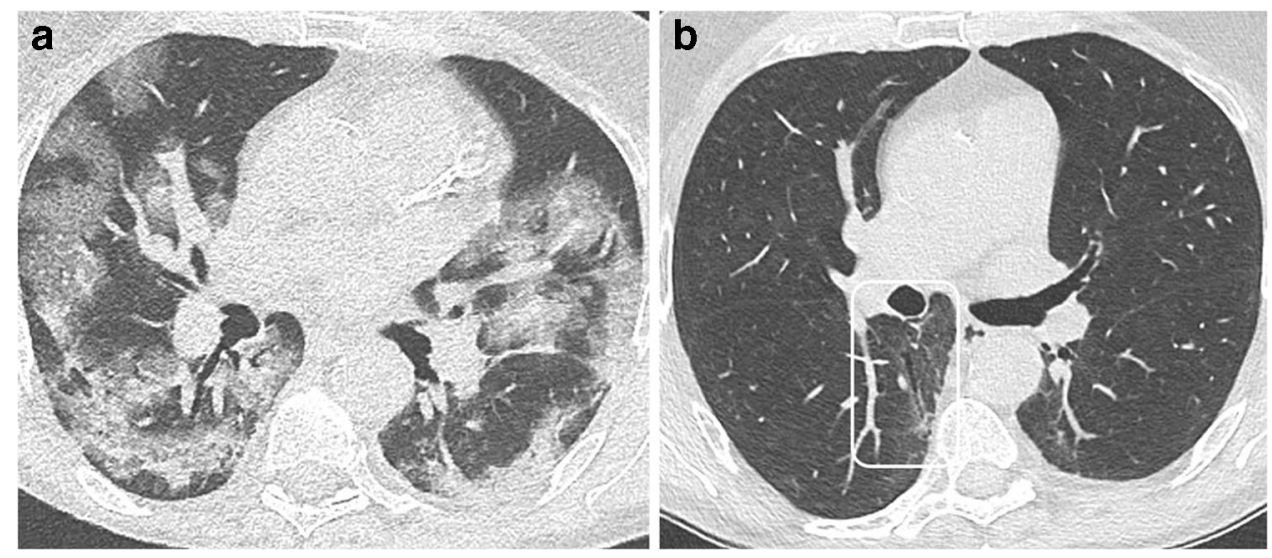

such as interlobular septal thickening, reticular opacity, and subpleural curvilinear opacities almost disappeared by month 9 with the predominant residual finding being ground glass opacities. Established fibrosis or progressive interstitial changes were not observed.

To summarize, most patients who were hospitalized in ICU for COVID-19 pneumonia still present with persisting $\mathrm{CT}$ abnormalities at 3-month follow-up. These abnormalities are probably consistent with residual post organizing pneumonia appearances and should not be described as fibrotic changes, since most are reversible and will continue to resolve up to 1 year post hospital discharge. The exact proportion of patients with long-term, irreversible fibrotic scarring is not clear, but seems to be low, probably close to $20 \%$ from the few papers published as of the time of writing, and based on what is known from the data on long-term changes seen on CT in ARDS patients. The proportion of patients with progressive fibrosis is expected to be even lower.

Importantly, there are also other causes of persistent dyspnea in COVID-19 pneumonia survivors, such as postintubation tracheal stenosis, deconditioning, sarcopenia, and depression which may affect those who have spent long periods in ICU [34].

Figures 1, 2, 3, 4, 5, and 6 illustrate the main CT features at 3-month and 6-month follow-ups. A glossary of appropriate terms to describe the post-COVID-19 pneumonia changes is provided in Table $1[12,36,37]$.

\section{Who should have imaging follow-up?}

In general, follow-up chest imaging in patients with community-acquired pneumonia is not routinely advised in patients whose symptoms have resolved within 5 to 7 days [38]. When follow-up imaging is performed, the rationale is to exclude an underlying malignancy, rather than to evaluate residual parenchymal findings. Predicting the respiratory consequences of COVID-19 is challenging. Experience from other coronavirus infections, including the worldwide outbreak of SARS and Middle East respiratory syndrome (MERS), suggests that the development of post-infection fibrosis is a concern $[39,40]$. Research shows development of lung fibrosis and persistence of abnormal findings on chest CT scans up to 7 years after symptom presentation $[32,41]$. Patients who were not hospitalized and have no clinical symptoms may not require imaging follow-up.

Taking into account the frequency of persistent lung abnormalities and the lack of data on long-term consequences, follow-up imaging should be considered in symptomatic patients who were hospitalized and/or showed a more severe clinical course of the disease. In these patients, chest CT is advised 3 months after hospital discharge. In patients who have non-resolving chest CT abnormalities, further investigations and repeated follow-up imaging after a further 3 months is advised. In all cases, imaging findings should be correlated with clinical findings and pulmonary function tests. Furthermore, chest CT imaging is advised in patients who present with new or progressive respiratory symptoms when recovering from COVID-19 pneumonia in order to assess possible complications such as pneumothorax or superimposed infection.

Pulmonary fibrosis related to the setting of ARDS is well recognized, with the majority of these patients developing histopathological evidence of fibrosis [9, 34, 42]. In view of the high prevalence of ARDS among COVID-19 pneumonia patients, the development of pulmonary fibrosis in this patient population is a concern $[43,44]$, and chest CT imaging in this particular group of patients is advised.

At the time of writing, specific guidelines for the longterm follow-up of COVID-19 pneumonia patients are limited. Guidelines on the respiratory follow-up of patients with a clinico-radiological diagnosis of COVID-19 pneumonia were published by the British Thoracic Society [23].

More evidence relating to this new syndrome will become available in the months to come, allowing guidelines to be updated and specific recommendations to be adjusted. Research on long-term follow-up of COVID-19 is needed to 
Table 1 Glossary. A proposal of a glossary of terms to describe CT findings in post-COVID-19 pneumonia based on the current literature [12, $36,37]$. Terms which are new compared to existing classifications in bold

\begin{tabular}{|c|c|}
\hline Terminology & Explanation \\
\hline $\begin{array}{l}\text { Low-density ground glass } \\
\text { opacity (GGO) }\end{array}$ & $\begin{array}{l}\text { Hazy increased lung opacity that preserves bronchial and vascular margins; it represents the progressive resolution } \\
\text { of GGO or consolidation following recovery from COVID-19 pneumonia }\end{array}$ \\
\hline Tinted sign & $\begin{array}{l}\text { GGO, which extends further into the lungs while decreasing in attenuation; it represents a possible finding follow- } \\
\text { ing resolution of COVID-19 pneumonia and it should not be interpreted as worsening disease }\end{array}$ \\
\hline Linear consolidation & $\begin{array}{l}\text { Subtle consolidation which runs parallel or perpendicular to the pleura; it can be observed in the late phase of } \\
\text { organizing pneumonia }\end{array}$ \\
\hline Parenchymal bands & Stripes which run parallel or perpendicular to the pleura, consistent with late-phase organizing pneumonia \\
\hline Perilobular opacities & $\begin{array}{l}\text { Opacity that borders the periphery of the secondary pulmonary lobule; it can involve interlobular septa, visceral } \\
\text { pleura, and lymphatics or veins; frequently observed in organizing pneumonia at any stage }\end{array}$ \\
\hline Reticulation & $\begin{array}{l}\text { Intra- and inter-lobular septal thickening; mild irregular reticulation may be seen in the late phase of COVID-19 } \\
\text { pneumonia }\end{array}$ \\
\hline Traction bronchiectasis & $\begin{array}{l}\text { It is usually a sign associated with pulmonary fibrosis; it can occur in the late phase of COVID-19 pneumonia and } \\
\text { should not be overcalled }\end{array}$ \\
\hline Bronchial distortion & $\begin{array}{l}\text { This term might be preferred over "traction bronchiectasis" when bronchial geometry is altered in the course of the } \\
\text { disease, while its irreversibility is yet to be confirmed. This might represent an interim finding during the course } \\
\text { of organizing pneumonia, with or without permanent sequelae. Because the terminology "traction bronchiectasis" } \\
\text { links straight to the classic pattern(s) of irreversible pulmonary fibrosis (with discrete potential of progressive dis- } \\
\text { ease), the term "bronchial distortion" might take on the description of morphology distortion in the follow-up of } \\
\text { COVID-19 pneumonia, until the irreversibility is actually confirmed. Similar lexicon might apply to fissure (e.g., } \\
\text { fissure distortion) and vessels (e.g., vessel distortion) into the broader representation of signs of distortion }\end{array}$ \\
\hline Fibrotic-like changes & $\begin{array}{l}\text { Include reticulation associated with bronchial dilatation and distortion in areas of consolidation or GGO; these can } \\
\text { be seen in the late phase of COVID-19 pneumonia. Fibrotic-like changes are potential precursors of fibrosis, but } \\
\text { there is a high probability that these will resolve with time }\end{array}$ \\
\hline Honeycombing & $\begin{array}{l}\text { Represents the CT feature of end-stage pulmonary fibrosis; uncommonly reported in the late phase of COVID-19 } \\
\text { pneumonia }\end{array}$ \\
\hline Mosaic attenuation pattern & $\begin{array}{l}\text { Abnormally hypodense areas corresponding to one or several contiguous secondary pulmonary lobules alternating } \\
\text { with normal or abnormally hyperdense areas (i.e., GGO); it has been described as a late feature of severe COVID- } \\
19 \text { pneumonia. It is still unclear whether it is due to residual small airway disease or microvascular thrombosis }\end{array}$ \\
\hline
\end{tabular}

clarify the term of persistence of these lung abnormalities as well as correlation with clinical findings.

\section{Which imaging modalities/protocols at which disease stage should be used?}

COVID-19 pneumonia is characterized by GGO as the predominant CT finding in the acute phase; moreover, some patients present with a transient increase in attenuation and the development of consolidation of variable extent and severity, and the development of linear consolidation, as a manifestation of organizing pneumonia.

Chest CT scans may be performed using a low-dose protocol, as reported by Dangis et al., who used a sub-millisievert effective radiation dose CT protocol and reported a diagnostic accuracy of $90.2 \%$, using real-time polymerase chain reaction (RT-PCR) as the standard of reference [45]. However, extremely low-dose protocol is discouraged in the follow-up because it could hamper the perception and the confidence of subtle diffuse GGO: noise and increasing strength of iterative reconstruction are not yet explored in this pattern of post-COVID-19 sequelae [46].
As for other lung diseases, additional CT acquisition in the prone position can be useful to distinguish mild or limited COVID-19 pneumonia from normal dependent density [47].

After discharge, CT protocols should be adapted to suit the clinical question. Minimum intensity projection (minIP) reformation may be useful to better depict residual abnormalities (Fig. 5).

Expiratory CT may be helpful if there is a suspicion of residual small airway disease. Dual-energy CT might be performed in dyspneic patients with decreased diffusing capacity (DLCO) if the unenhanced inspiratory CT scan appears normal or minimally abnormal to help identify possible perfusion defects secondary to microvascular thrombosis [48].

As mentioned earlier, there are potential causes of persisting dyspnea other than lung fibrosis or microvascular thrombosis, such as post-intubation tracheal stenosis, which can be overlooked if the cervical portion of the trachea is not included on the CT scan.

To summarize, unenhanced low-dose CT performed supinely should be sufficient in the vast majority of COVID19 patients, both in the acute phase and on follow-up. Expiratory CT and single- or dual-energy contrast-enhanced 
studies should only be performed on selected patients, after clinical and functional evaluation (see supplementary material).

\section{The role of pulmonary angiography CT and dual-energy CT}

Patients infected with SARS-Cov-2 are at risk of thromboembolic complications, due to the activation of coagulation linked to the immune response. Severe COVID-19 pneumonia is associated with increased levels of inflammatory and prothrombotic biomarkers such as interleukin-6, which play a fundamental role in the activation of the extrinsic coagulation route and suppress the fibrinolytic system [49]. Furthermore, it has been demonstrated that SARS-Cov-2 has the capacity to directly infect the alveolar endothelial cells and induce endothelitis, which can also promote local thrombosis [50]. There is now an established awareness of the increased risk of pulmonary embolism (PE) from numerous articles reporting PE in COVID-19 pneumonia patients, with the consequent possible risk of the over-use of CT pulmonary angiography (CTPA) [51-59].

However, the reported incidence of PE varies widely, from less than $6 \%$ when CTPA is systematically performed at the initial presentation of unselected patients [51] to $30-38 \%$ when CTPA is performed in severely ill patients admitted to ICU [59]. A meta-analysis including 27 studies with 3342 patients reported that PE was more frequently found in severely ill patients. The pooled incidence rates were $24.7 \%$ (95\% CI: $18.6,32.1$ ) in patients who were critically ill or who were admitted to ICU vs. $10.5 \%$ (95\% CI: $5.1,20.2)$ for patients who were not admitted to ICU [60]. Another meta-analysis based on 3487 patients from 30 studies reported venous thromboembolism (VTE) in $24 \%$ of patients admitted to ICU, and in $9 \%$ of patients from normal wards [61]. Even though the symptoms of COVID19 pneumonia and pulmonary embolism strongly overlap, especially dyspnea and/or oxygen desaturation, there is no current recommendation to routinely perform a CTPA when evaluating COVID-19 pneumonia patients. The 2020 advice from the European Society of Radiology and the European Society of Thoracic Imaging was to consider performing an additional contrast-enhanced CT acquisition for patients requiring supplementary oxygen if there was limited disease extension on the unenhanced CT [16].

D-dimer elevation has been recognized as a useful biomarker of poor prognosis; D-dimer levels are now almost invariably checked in COVID-19 pneumonia patients [62]. This greatly increases the referral rate for CTPA, with a risk of over-use. The best cutoff for predicting VTE in COVID19 pneumonia patients has still not been determined. The acceptable maximum failure rate of PE diagnostic strategies should be adapted to the prevalence of PE in the specific population, according to the recommendation of the Scientific and Standardization Committee (SSC) of the International Society of Thrombosis and Haemostasis (ISTH) [63]. In COVID-19 pneumonia outpatients or inpatients from normal wards where PE prevalence is low, using other D-dimer cutoffs as those used in the general population might expose to unacceptable failure rates, whereas higher thresholds could potentially be used for ICU patients. Mouhat et al. identified $2590 \mathrm{ng} \cdot \mathrm{mL}^{-1}$ to be the best independent predictor of PE in their predominantly inpatient COVID-19 pneumonia population, in whom the PE prevalence was 27\% [64].

Dual-energy CT (DECT) enables assessment of pulmonary perfusion and the detection of capillary microvascular thrombosis, which has been reported to occur in severe COVID-19 pneumonia patients [65]. In the acute setting, DECT has been reported to demonstrate increased perfusion in areas of GGO. The loss of physiological hypoxic vasoconstriction induces pulmonary shunting, which may explain the profound hypoxemia observed in some COVID19 pneumonia patients [66]. DECT has also been used in patients after discharge. Diffuse hypo-perfused areas were reported in 3 patients with dyspnea on minimal exertion and no remaining parenchymal CT anomalies [48]. If validated in larger series, DECT might be used in patients with persisting abnormal gas exchange despite apparent normalization of lung parenchyma on CT. To date, there is no evidence in the literature that macro-vascular disease plays a role in long COVID or post-COVID syndrome. If there are still peripheral perfusion deficits in the late follow-up is unclear and subject to current investigation [48]. Therefore, currently, CTPA is only suggested if there is further evidence of PE following the general consideration of pre-test probability and D-dimers, especially if supplementary oxygen is needed in patients with limited disease extension [16]. Additionally, CTPA can be considered in the follow-up of patients who had PE in the acute phase of the disease.

\section{Conclusion}

Most patients show residual disease at discharge. PostCOVID-19 pneumonia changes are mainly consistent with prior organizing pneumonia and are likely to disappear within 12 months of recovery from the acute infection in the majority of patients. "Fibrotic-like" changes are potential precursors of fibrosis, but there is a high probability that these will resolve over time. Consequently, imaging followup should be performed after a delay to allow resolution of the reversible inflammatory process in symptomatic patients. Unenhanced low-dose CT performed supinely should be sufficient in the vast majority of COVID-19 patients for follow-up. Expiratory CT and single- or dual-energy 
contrast-enhanced studies should only be performed on selected patients, after clinical and functional evaluation.

Supplementary Information The online version contains supplementary material available at https://doi.org/10.1007/s00330-021-08317-7.

Funding Open Access funding provided by Universität Zürich.

\section{Declarations}

Guarantor The scientific guarantor of this publication is Prof. Thomas Frauenfelder.

Conflict of interest The authors of this manuscript declare no relationships with any companies whose products or services may be related to the subject matter of the article.

Statistics and biometry No complex statistical methods were necessary for this paper.

Informed consent Not applicable

Ethical approval Not applicable

\section{Methodology}

- Special report

Open Access This article is licensed under a Creative Commons Attribution 4.0 International License, which permits use, sharing, adaptation, distribution and reproduction in any medium or format, as long as you give appropriate credit to the original author(s) and the source, provide a link to the Creative Commons licence, and indicate if changes were made. The images or other third party material in this article are included in the article's Creative Commons licence, unless indicated otherwise in a credit line to the material. If material is not included in the article's Creative Commons licence and your intended use is not permitted by statutory regulation or exceeds the permitted use, you will need to obtain permission directly from the copyright holder. To view a copy of this licence, visit http://creativecommons.org/licenses/by/4.0/.

\section{References}

1. Mahase E (2020) Covid-19: what do we know about "long covid"? BMJ 370:m2815. https://doi.org/10.1136/bmj.m2815

2. Greenhalgh T, Knight M, A'Court C et al (2020) Management of post-acute covid-19 in primary care. BMJ 370:m3026. https://doi. org/10.1136/bmj.m3026

3. Sudre CH, Murray B, Varsavsky T et al (2021) Attributes and predictors of long COVID. Nat Med 27:626-631. https://doi.org/ 10.1038/s41591-021-01292-y

4. Ojo AS, Balogun SA, Williams OT, Ojo OS (2020) Pulmonary fibrosis in COVID-19 survivors: predictive factors and risk reduction strategies. Pulm Med 2020:e6175964. https://doi.org/10. $1155 / 2020 / 6175964$

5. Wunsch H (2020) Mechanical Ventilation in COVID-19: interpreting the current epidemiology. Am J Respir Crit Care Med 202:1-4. https://doi.org/10.1164/rccm.202004-1385ED

6. Torres A, Niederman MS, Chastre J et al (2017) International ERS/ESICM/ESCMID/ALAT guidelines for the management of hospital-acquired pneumonia and ventilator-associated pneumonia: guidelines for the management of hospital-acquired pneumonia (HAP)/ventilator-associated pneumonia (VAP) of the European Respiratory Society (ERS), European Society of Intensive Care Medicine (ESICM), European Society of Clinical Microbiology and Infectious Diseases (ESCMID) and AsociaciónLatinoamericana del Tórax (ALAT). Eur Respir J 50:1700582. https://doi.org/10.1183/13993003.00582-2017

7. Maes M, Higginson E, Pereira-Dias J et al (2021) Ventilatorassociated pneumonia in critically ill patients with COVID-19. Crit Care 25:25. https://doi.org/10.1186/s13054-021-03460-5

8. Cabrera-Benitez NE, Laffey JG, Parotto M et al (2014) Mechanical ventilation-associated lung fibrosis in acute respiratory distress syndrome: a significant contributor to poor outcome. Anesthesiology 121:189-198. https://doi.org/10.1097/ALN.0000000000000264

9. Thille AW, Esteban A, Fernández-Segoviano P et al (2013) Chronology of histological lesions in acute respiratory distress syndrome with diffuse alveolar damage: a prospective cohort study of clinical autopsies. Lancet Respir Med 1:395-401. https://doi. org/10.1016/S2213-2600(13)70053-5

10. Wigén J, Löfdahl A, Bjermer L et al (2020) Converging pathways in pulmonary fibrosis and Covid-19 - the fibrotic link to disease severity. Respir Med X 2:100023. https://doi.org/10.1016/j.yrmex. 2020.100023

11. Mineo G, Ciccarese F, Modolon C et al (2012) Post-ARDS pulmonary fibrosis in patients with $\mathrm{H} 1 \mathrm{~N} 1$ pneumonia: role of follow-up CT. Radiol Med 117:185-200. https://doi.org/10.1007/ s11547-011-0740-3

12. Han X, Fan Y, Alwalid O et al (2021) Six-month follow-up chest CT findings after severe COVID-19 pneumonia. Radiology 299:E177-E186. https://doi.org/10.1148/radiol.2021203153

13. Lerum TV, Aaløkken TM, Brønstad E et al (2020) Dyspnoea, lung function and CT findings three months after hospital admission for COVID-19. Eur Respir J. https://doi.org/10.1183/13993003. 03448-2020

14. Yang ZL, Chen C, Huang L et al (2020) Fibrotic changes depicted by thin-section CT in patients with COVID-19 at the early recovery stage: preliminary experience. Front Med (Lausanne) 7:605088. https://doi.org/10.3389/fmed.2020.605088

15. Nalbandian A, Sehgal K, Gupta A et al (2021) Post-acute COVID19 syndrome. Nat Med 27:601-615. https://doi.org/10.1038/ s41591-021-01283-z

16. Revel M-P, Parkar AP, Prosch H et al (2020) COVID-19 patients and the radiology department - advice from the European Society of Radiology (ESR) and the European Society of Thoracic Imaging (ESTI). Eur Radiol. https://doi.org/10.1007/ s00330-020-06865-y

17. Sah A, Fabian EJ, Remolina C (2021) Ventilator-induced barotrauma in critically ill patients with COVID-19: a retrospective observational study. J Community Hosp Intern Med Perspect 11:304-310. https://doi.org/10.1080/20009666.2021.1896831

18. McGuinness $\mathrm{G}$, Zhan $\mathrm{C}$, Rosenberg $\mathrm{N}$ et al (2020) Increased Incidence of barotrauma in patients with COVID-19 on invasive mechanical ventilation. Radiology 297:E252-E262. https://doi. org/10.1148/radiol.2020202352

19. Liu K, Zeng Y, Xie P et al (2020) COVID-19 with cystic features on computed tomography: a case report. Medicine (Baltimore) 99:e20175. https://doi.org/10.1097/MD.0000000000020175

20. Liu C, Ye L, Xia R et al (2020) Chest computed tomography and clinical follow-up of discharged patients with COVID-19 in Wenzhou City, Zhejiang, China. Ann Am Thorac Soc 17:1231-1237. https://doi.org/10.1513/AnnalsATS.202004-324OC

21. Liu D, Zhang W, Pan F et al (2020) The pulmonary sequalae in discharged patients with COVID-19: a short-term observational study. Respir Res 21:125. https://doi.org/10.1186/ s12931-020-01385-1 
22. Wang Y, Dong C, Hu Y et al (2020) Temporal changes of CT findings in 90 patients with COVID-19 pneumonia: a longitudinal study. Radiology 296:E55-E64. https://doi.org/10.1148/radiol. 2020200843

23. George PM, Barratt SL, Condliffe R et al (2020) Respiratory follow-up of patients with COVID-19 pneumonia. Thorax 75:1009 1016. https://doi.org/10.1136/thoraxjnl-2020-215314

24. Froidure A, Mahsouli A, Liistro G et al (2021) Integrative respiratory follow-up of severe COVID-19 reveals common functional and lung imaging sequelae. Respir Med 181:106383. https://doi. org/10.1016/j.rmed.2021.106383

25. Balbi M, Conti C, Imeri G et al (2021) Post-discharge chest CT findings and pulmonary function tests in severe COVID-19 patients. Eur J Radiol 138:109676. https://doi.org/10.1016/j.ejrad. 2021.109676

26. van den Borst B, Peters JB, Brink M et al (2020) Comprehensive health assessment three months after recovery from acute COVID-19. Clin Infect Dis. https://doi.org/10.1093/cid/ciaa1 750

27. Zhao Y-M, Shang Y-M, Song W-B et al (2020) Follow-up study of the pulmonary function and related physiological characteristics of COVID-19 survivors three months after recovery. EClinicalMedicine 25:100463. https://doi.org/10.1016/j.eclinm. 2020.100463

28. González J, Benítez ID, Carmona P et al (2021) Pulmonary function and radiologic features in survivors of critical COVID19: a 3-month prospective cohort. Chest. https://doi.org/10. 1016/j.chest.2021.02.062

29. Tabatabaei SMH, Rajebi H, Moghaddas F et al (2020) Chest CT in COVID-19 pneumonia: what are the findings in mid-term follow-up? Emerg Radiol 27:711-719. https://doi.org/10.1007/ s10140-020-01869-z

30. Guler SA, Ebner L, Aubry-Beigelman C et al (2021) Pulmonary function and radiological features 4 months after COVID-19: first results from the national prospective observational Swiss COVID-19 lung study. Eur Respir J 57:2003690. https://doi.org/ 10.1183/13993003.03690-2020

31. Ebner L, Funke-Chambour M, von Garnier C et al (2020) Imaging in the aftermath of COVID-19: what to expect. Eur Radiol. https://doi.org/10.1007/s00330-020-07465-6

32. Wu X, Dong D, Ma D (2016) Thin-section computed tomography manifestations during convalescence and long-term followup of patients with severe acute respiratory syndrome (SARS). Med Sci Monit 22:2793-2799. https://doi.org/10.12659/msm. 896985

33. Liu M, Lv F, Huang Y, Xiao K (2021) Follow-up study of the chest CT characteristics of COVID-19 survivors seven months after recovery. Front Med (Lausanne) 8:636298. https://doi.org/ 10.3389/fmed.2021.636298

34. Herridge MS, Tansey CM, Matté A et al (2011) Functional disability 5 years after acute respiratory distress syndrome. $\mathrm{N}$ Engl $\mathrm{J}$ Med 364:1293-1304. https://doi.org/10.1056/NEJMoa1011802

35. Wu X, Liu X, Zhou Y et al (2021) 3-month, 6-month, 9-month, and 12-month respiratory outcomes in patients following COVID19-related hospitalisation: a prospective study. Lancet Respir Med. https://doi.org/10.1016/S2213-2600(21)00174-0

36. Hansell DM, Bankier AA, MacMahon H et al (2008) Fleischner Society: glossary of terms for thoracic imaging. Radiology 246:697-722. https://doi.org/10.1148/radiol.2462070712

37. Wells AU, Devaraj A, Desai SR (2021) Interstitial lung disease after COVID-19 infection: a catalog of uncertainties. Radiology 299:E216-E218. https://doi.org/10.1148/radiol.2021204482

38. Metlay JP, Waterer GW, Long AC et al (2019) Diagnosis and treatment of adults with community-acquired pneumonia. An official clinical practice guideline of the American Thoracic Society and
Infectious Diseases Society of America. Am J Respir Crit Care Med 200:e45-e67. https://doi.org/10.1164/rccm.201908-1581ST

39. Antonio GE, Wong KT, Hui DSC et al (2003) Thin-section CT in patients with severe acute respiratory syndrome following hospital discharge: preliminary experience. Radiology 228:810-815. https://doi.org/10.1148/radiol.2283030726

40. Chan KS, Zheng JP, Mok YW et al (2003) SARS: prognosis, outcome and sequelae. Respirology 8(Suppl):S36-40. https://doi. org/10.1046/j.1440-1843.2003.00522.x

41. Das KM, Lee EY, Singh R et al (2017) Follow-up chest radiographic findings in patients with MERS-CoV after recovery. Indian J Radiol Imaging 27:342-349. https://doi.org/10.4103/ ijri.IJRI_469_16

42. Burnham EL, Hyzy RC, Paine R et al (2014) Detection of fibroproliferation by chest high-resolution CT scan in resolving ARDS. Chest 146:1196-1204. https://doi.org/10.1378/chest.13-2708

43. McDonald LT (2021) Healing after COVID-19: are survivors at risk for pulmonary fibrosis? Am J Physiol Lung Cell Mol Physiol 320:L257-L265. https://doi.org/10.1152/ajplung.00238. 2020

44. Dmytriw AA, Chibbar R, Chen PPY et al (2021) Outcomes of acute respiratory distress syndrome in COVID-19 patients compared to the general population: a systematic review and metaanalysis. Expert Rev Respir Med 15:1347-1354. https://doi.org/ 10.1080/17476348.2021.1920927

45 Dangis A, Gieraerts C, De Bruecker Y et al (2020) Accuracy and reproducibility of low-dose submillisievert chest CT for the diagnosis of COVID-19. Radiol Cardiothorac Imaging 2:e200196. https://doi.org/10.1148/ryct.2020200196

46. Avila RS, Fain SB, Hatt C et al (2021) QIBA guidance: computed tomography imaging for COVID-19 quantitative imaging applications. Clin Imaging 77:151-157. https://doi.org/10.1016/j.clini mag.2021.02.017

47. Kashiwabara K, Kohshi S-I (2006) Additional computed tomography scans in the prone position to distinguish early interstitial lung disease from dependent density on helical computed tomography screening patient characteristics. Respirology 11:482-487. https:// doi.org/10.1111/j.1440-1843.2006.00869.x

48. Patelli G, Paganoni S, Besana F et al (2020) Preliminary detection of lung hypoperfusion in discharged Covid-19 patients during recovery. Eur J Radiol 129:109121. https://doi.org/10.1016/j. ejrad.2020.109121

49. Lopez-Castaneda S, García-Larragoiti N, Cano-Mendez A et al (2021) Inflammatory and prothrombotic biomarkers associated with the severity of COVID-19 infection. Clin Appl Thromb Hemost 27:1076029621999099. https://doi.org/10.1177/10760 29621999099

50. Varga Z, Flammer AJ, Steiger P et al (2020) Endothelial cell infection and endotheliitis in COVID-19. Lancet 395:1417-1418. https://doi.org/10.1016/S0140-6736(20)30937-5

51. Jalaber C, Revel M-P, Chassagnon G et al (2020) Role of upfront CT pulmonary angiography at admission in COVID-19 patients. Thromb Res 196:138-140. https://doi.org/10.1016/j.thromres. 2020.08.037

52. Poyiadji N, Cormier P, Patel PY et al (2020) Acute pulmonary embolism and COVID-19. Radiology 297:E335-E338. https:// doi.org/10.1148/radiol.2020201955

53. Ooi MWX, Rajai A, Patel R et al (2020) Pulmonary thromboembolic disease in COVID-19 patients on CT pulmonary angiography - prevalence, pattern of disease and relationship to D-dimer. Eur J Radiol 132:109336. https://doi.org/10.1016/j.ejrad.2020. 109336

54. Klok FA, Kruip MJHA, van der Meer NJM et al (2020) Incidence of thrombotic complications in critically ill ICU patients with COVID-19. Thromb Res 191:145-147. https://doi.org/10.1016/j. thromres.2020.04.013 
55. Alonso-Fernández A, Toledo-Pons N, Cosío BG et al (2020) Prevalence of pulmonary embolism in patients with COVID-19 pneumonia and high D-dimer values: a prospective study. PLoS One 15:e0238216. https://doi.org/10.1371/journal.pone.0238216

56. Grillet F, Behr J, Calame P et al (2020) Acute pulmonary embolism associated with COVID-19 pneumonia detected with pulmonary CT angiography. Radiology 296:E186-E188. https://doi.org/ 10.1148/radiol.2020201544

57 Xie Y, Wang X, Yang P, Zhang S (2020) COVID-19 complicated by acute pulmonary embolism. Radiol Cardiothorac Imaging 2:e200067. https://doi.org/10.1148/ryct.2020200067

58. Bompard F, Monnier H, Saab I et al (2020) Pulmonary embolism in patients with COVID-19 pneumonia. Eur Respir J 56:2001365. https://doi.org/10.1183/13993003.01365-2020

59. Léonard-Lorant I, Delabranche X, Séverac F et al (2020) Acute pulmonary embolism in patients with COVID-19 at CT angiography and relationship to D -dimer levels. Radiology 296:E189E191. https://doi.org/10.1148/radiol.2020201561

60. Suh YJ, Hong H, Ohana M et al (2020) Pulmonary embolism and deep vein thrombosis in COVID-19: a systematic review and meta-analysis. Radiology 298:E70-E80. https://doi.org/10.1148/ radiol.2020203557

61. Porfidia A, Valeriani E, Pola R et al (2020) Venous thromboembolism in patients with COVID-19: systematic review and metaanalysis. Thromb Res 196:67-74. https://doi.org/10.1016/j.throm res.2020.08.020
62. Chocron R, Duceau B, Gendron N et al (2021) D-dimer at hospital admission for COVID-19 are associated with in-hospital mortality, independent of venous thromboembolism: insights from a French multicenter cohort study. Arch Cardiovasc Dis. https://doi. org/10.1016/j.acvd.2021.02.003

63. Dronkers CEA, van der Hulle T, Gal GL et al (2017) Towards a tailored diagnostic standard for future diagnostic studies in pulmonary embolism: communication from the SSC of the ISTH. J Thromb Haemost 15:1040-1043. https://doi.org/10.1111/jth. 13654

64. Mouhat B, Besutti M, Bouiller K et al (2020) Elevated D-dimers and lack of anticoagulation predict PE in severe COVID-19 patients. Eur Respir J 56:2001811. https://doi.org/10.1183/13993 003.01811-2020

65. Patel BV, Arachchillage DJ, Ridge CA et al (2020) Pulmonary angiopathy in severe COVID-19: physiologic, imaging, and hematologic observations. Am J Respir Crit Care Med 202:690-699. https://doi.org/10.1164/rccm.202004-1412OC

66. Si-Mohamed S, Chebib N, Sigovan M et al (2020) In vivo demonstration of pulmonary microvascular involvement in COVID19 using dual-energy computed tomography. Eur Respir J 56:2002608. https://doi.org/10.1183/13993003.02608-2020

Publisher's note Springer Nature remains neutral with regard to jurisdictional claims in published maps and institutional affiliations. 